\title{
Optimization of System Parameters of Packed Bed Solar Energy Storage System having Storage Material Elements of Large Size
}

\author{
Ranjit Singh ${ }^{*}, 1$ R.P. Saini ${ }^{2}$ and J.S. Saini ${ }^{3}$ \\ ${ }^{I}$ Department of Mechanical Engineering, Beant College of Engineering and Technology, Gurdaspur, Punjab, 143521, India \\ ${ }^{2}$ Alternate Hydro Energy Centre, ${ }^{3}$ Department of Mechanical and Industrial Engineering, Indian Institute of Technology \\ Roorkee, Roorkee, Uttarakhand, 247667, India
}

\begin{abstract}
Major concern for design of a packed bed solar energy storage system is to maximize heat transfer during charging and discharging phase by spending minimum amount of pumping power. Shape of the material elements and void fraction of the bed are the system parameters for a given material size, which could affect heat transfer and pressure drop in the bed considerably. In the present study, simulation has been carried out to evaluate optimum values of system parameters in order to have the best thermo hydraulic performance of packed bed solar energy storage system. Five different shapes of large size material elements have been analyzed to carry out the present optimization study. In order to select optimum values of system parameters under the given operating conditions, design plots have been prepared and presented in the paper.
\end{abstract}

Keywords: Packed bed, solar air heater, thermal energy storage.

\section{INTRODUCTION}

Solar energy is considered to be a dominating renewable energy source due to its large potential. In order to face future energy crisis and threat to environment with the use of fossil fuels, development of technologies for an efficient and effective use of this energy source is the need of the day. However, intermittent nature of solar energy demands an integration of energy storage system with the solar collectors in order to make the solar energy source more reliable. Packed bed is well known thermal energy storage system for air based solar energy utilization system. Energy stored in a packed bed may be useful to have uninterrupted supply of energy in the absence of solar radiation and also to fulfill the peak load energy demand even in the presence of solar radiation. Packed bed consists of material elements packed in a container. During charging phase, hot air from solar collector flows through the bed from top to bottom in order to transfer thermal energy to the storage material. Stored energy can be extracted by making flow of air from bottom to top of the bed during discharging phase.

Schmidt and Willmott [1] mentioned that the distinct disadvantage of packed bed is the large pressure drop due to packing of small size material elements, which causes a large amount of energy consumption to propel hot air through the bed. The literature reveals that system design must be based on the methods to reduce pressure drop in the bed in order to enhance the effective use of the solar energy system. Sagara and Nakahara [2] reported that packing of large size storage material elements could be used to reduce the pressure drop. Singh et al. [3] reported an extensive experimental investigation to analyze the effect of shape of large size material elements and void fraction of the bed on performance of the system under the

*Address correspondence to this author at the Department of Mechanical Engineering, Beant College of Engineering and Technology, Gurdaspur, Punjab, 143521, India; Tel: +91 1874 221464;

E-mail: rsolar70@yahoo.co.in

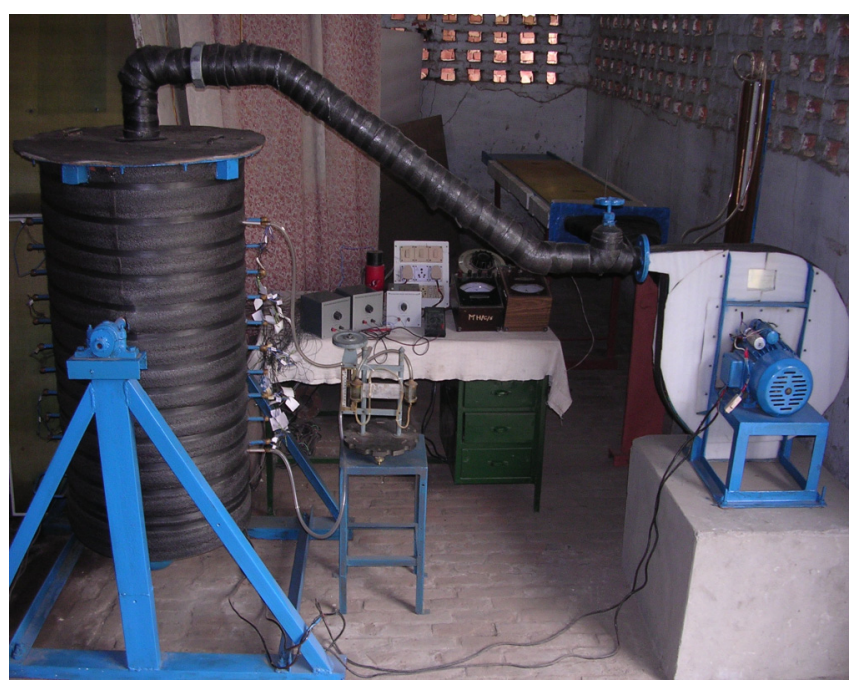

Fig. (1). Photograph showing experimental set-up.

Table 1. Range of System and Operating Parameters

\begin{tabular}{|c|c|}
\hline Parameter & Range \\
\hline \hline Sphericity $(\psi)$ & $0.55-1.00$ \\
\hline Void fraction $(\varepsilon)$ & $0.306-0.630$ \\
\hline Reynolds number $(\mathrm{Re})$ & $1257-2157$ (T-joint tile bricks, $\psi=0.55)$ \\
& $1047-1797$ (standard tile bricks, $\psi=0.63$ ) \\
& $1257-2157$ (standard bricks, $\psi=0.72)$ \\
& $1558-2674$ (concrete cubes, $\psi=0.80)$ \\
& $1139-1955$ (concrete spheres, $\psi=1.00)$ \\
\hline
\end{tabular}

given operating conditions. The experimental set-up and range of parameters used for this investigation are shown in Fig. (1) and Table 1 respectively. In order to predict thermal and 
hydraulic performance of the system, Nusselt number and friction factor correlations as a function of Reynolds number, sphericity and void fraction of the bed are reported by the authors. Based on these correlations, Singh et al. [4-6] reported simulated performance of packed bed solar energy storage system. It is revealed from the results of simulated performance that there is a need to evaluate optimum values of system parameters in order to have best thermo hydraulic performance of the packed bed solar energy storage system. In the present paper, optimization procedure has been reported and discussed to evaluate optimum values of system parameters. Results of optimization study have been presented in the form of design plots, which can be used by a designer to select optimum values of system parameter under the given operating conditions.

\section{OPTIMIZATION OF SYSTEM PARAMETERS}

Thermal energy stored in the bed and energy consumption by fan to propel air through the bed need attention to evaluate optimum values of system parameters. The system should be designed in such a way that leads to minimum energy consumption by fan per unit energy stored/extracted. This amounts to maximizing the ratio of thermal energy stored/extracted to energy consumption by the fan. However such a comparison of energy quantities i.e. thermal energy of the storage and work energy consumption by the fan has not been found to be reasonable because of the difference in the grades of energy quantities being compared; the work energy being higher grade energy as compared to thermal energy. It has therefore been found reasonable to compare these energy quantities by converting them to the same grade of energy. Torab and Beasley [7] reported that to make a compromise between available energy stored and work energy consumption by fan, the ratio of these two quantities should be maximized. Therefore the ratio of these two quantities expressed as ' $\mathrm{Q}_{\mathrm{at}} / \mathrm{W}_{\mathrm{t}}$ ' has been chosen as the optimization parameter for carrying out the process of optimization. Such an optimization process also known as thermo hydraulic optimization accounts for thermal as well as hydraulic (fluid flow) considerations of the system performance.

Optimization process seeks to determine a set of values of the system parameters i.e. sphericity $(\psi)$ of material elements and void fraction $(\varepsilon)$ of the bed that yield a maximum value of the optimization parameter ' $\mathrm{Q}_{\mathrm{a}} / \mathrm{W}_{\mathrm{t}}$ '. In order to carry out the present optimization study, data of total available energy stored in the bed ' $\mathrm{Q}_{\mathrm{at}}$ ' and total work energy consumption by fan ' $\mathrm{W}_{\mathrm{t}}$ ' reported by Singh et al. [5, 6] have been utilized. Accordingly, plots of optimization parameter against void fraction of the bed at different sphericity values of material elements are shown in Fig. (2). It is observed that the maximum value of optimization parameter ' $\mathrm{Q}_{\mathrm{at}} / \mathrm{W}_{\mathrm{t}}$ ' corresponds to a void fraction of 0.45 for each value of the sphericity. In case of sphericity value of 1.00 i.e. the bed of spheres, only single point is shown in the plot because for the bed of spheres, only single value of void fraction $(\varepsilon=0.40)$ is considered due to the reason described by Singh et $a l$. [3]. In these plots, highest value of ' $\mathrm{Q}_{\mathrm{a}} / \mathrm{W}_{\mathrm{t}}$ ' corresponds to sphericity of 0.80 i.e. the bed of cubes. Therefore the present simulation study resulted into optimum values of system parameters i.e. sphericity $(\psi)$ equal to 0.80 and void fraction $(\varepsilon)$ equal to 0.45 under the given operating conditions.

It may be noted that although optimum values of system parameters were determined for arbitrary values of storage volume and bed length; it was verified that the choice of storage size and length did not have any effect on optimum values of these parameters.

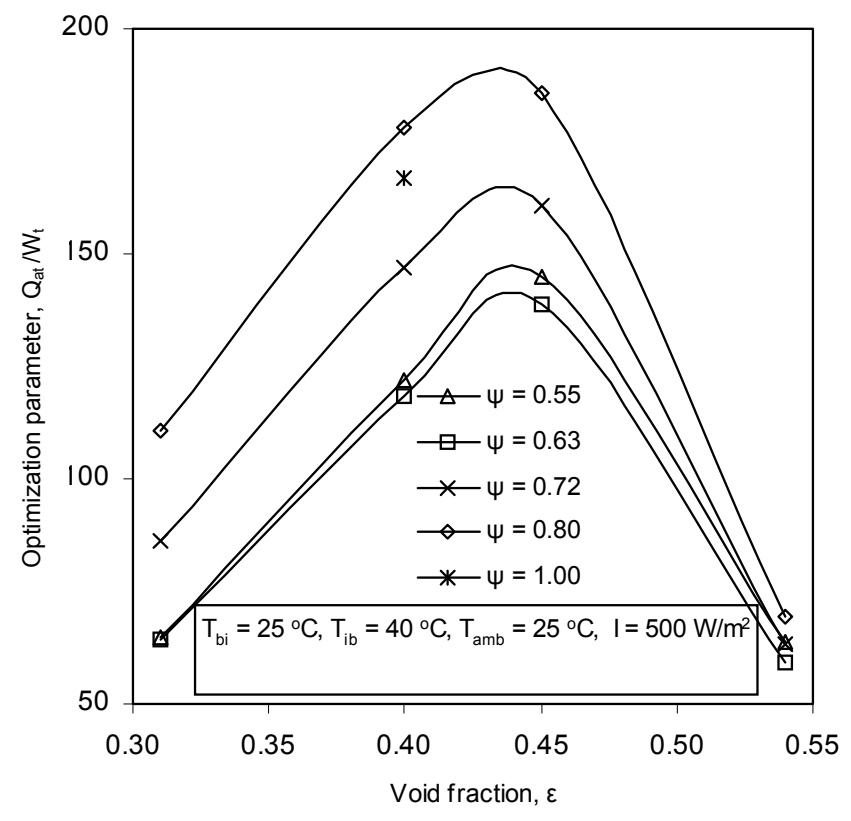

Fig. (2). Variation of optimization parameter with change of void fraction of the bed for material elements of different shapes.

\section{OPTIMIZATION PLOTS}

Design criterion of a solar energy thermal system is normally based on the following operating parameters:

(i). Temperature rise $(\Delta \mathrm{T})$ : The temperature rise above the ambient temperature for storage system is determined as per the requirement.

(ii). Average Insolation (I) : This is the value of intensity of solar radiation averaged over the period of utilization of energy and measured for a place where the system is to be located.

The ratio of these two operating parameters is known as temperature rise parameter $(\Delta \mathrm{T} / \mathrm{I})$. The typical value of temperature rise parameter lies between 0 to $0.15^{\circ} \mathrm{C} \mathrm{m}^{2} / \mathrm{W}$ for solar air heating applications.

Fig. (2) shows optimum value of sphericity $(\psi)$ and void fraction $(\varepsilon)$ corresponding to a temperature difference, $\Delta \mathrm{T}$ of $15^{\circ} \mathrm{C}$ and average solar radiation of $500 \mathrm{~W} / \mathrm{m}^{2}$ i.e. at a value of temperature rise parameter ' $\Delta \mathrm{T} / \mathrm{I}$ ' equal to 0.03 . However, it was required to evaluate optimum values of these system parameters for a range of temperature rise parameter ' $\Delta \mathrm{T} / \mathrm{I}$ '. Therefore values of optimization parameter ' $\mathrm{Q}_{\mathrm{at}} / \mathrm{W}_{\mathrm{t}}$ ' were evaluated for a range of temperature rise parameter ' $\Delta \mathrm{T} / \mathrm{I}$ ' at an average insolation ' $\mathrm{I}$ ' equal to $500 \mathrm{~W} / \mathrm{m}^{2}$ and $1000 \mathrm{~W} / \mathrm{m}^{2}$. Maximum value of optimization parameter ' $\mathrm{Q}_{\mathrm{at}} / \mathrm{W}_{\mathrm{t}}$ ' was determined for each set of temperature rise parameter, ${ }^{\prime} \Delta \mathrm{T} / \mathrm{I}$ ' and solar radiation, 'I'. Subsequently, optimum values of system parameters were determined.

It was considered to be appropriate to prepare design plots with the help of optimum values of system parameters as a function of temperature rise parameter as shown in Figs. $(3,4)$ respectively. It can be observed from these plots that effect of 
variation of average insolation on the optimum values of system parameters appears to be negligible.

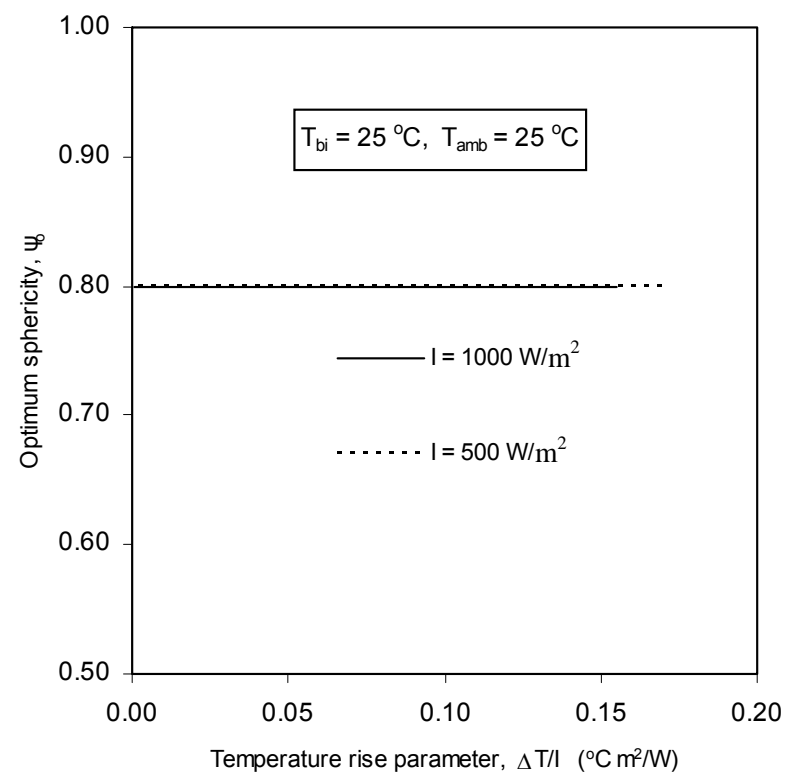

Fig. (3). Design plot showing the effect of temperature rise parameter on an optimum value of sphericity of material elements.

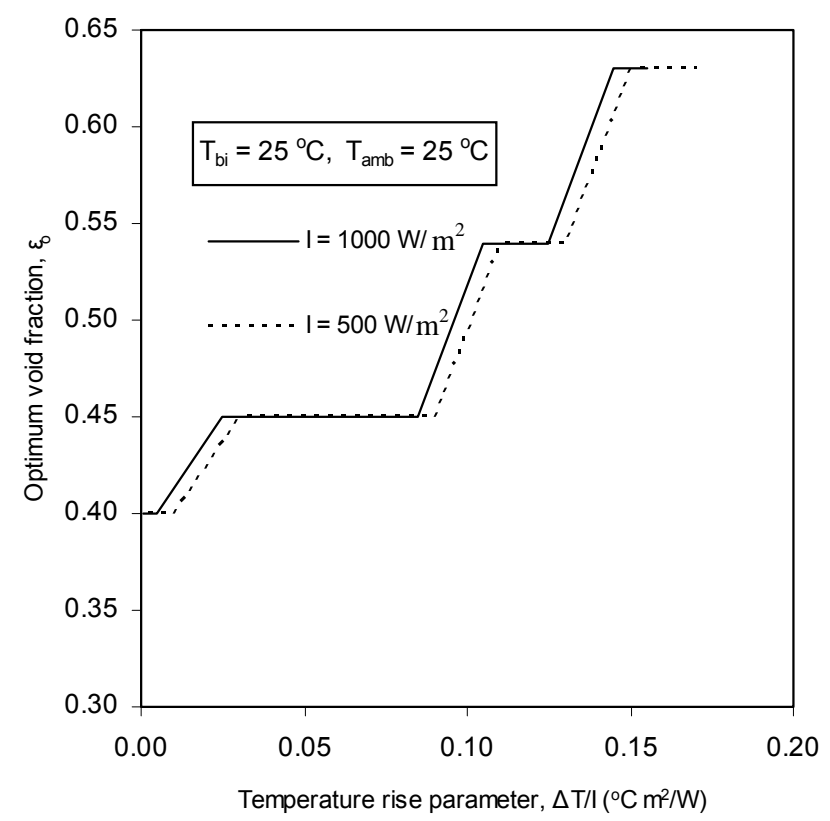

Fig. (4). Design plot showing the effect of temperature rise parameter on an optimum value of void fraction of the bed.

Further it can also be noted in the present optimization study that to have the best thermo hydraulic performance of the packed bed energy storage system for a given value of operating parameter ' $\Delta \mathrm{T} / \mathrm{I}$ ' in the range of investigation, the designer can select optimum values of sphericity and void fraction from the design plots shown in Figs. $(\mathbf{3}, \mathbf{4})$ respectively. These plots can be utilized for any value of average insolation because the effect of insolation on optimum values of the system parameters is found to be negligible.

\section{CONCLUSION}

In the present paper an attempt has been made to evaluate optimum values of system parameters for having best thermo hydraulic performance of packed bed solar energy storage system. Five different shapes of large size storage material elements have been analyzed to carry out the present optimization study. Design plots are found to be a good tool for designer in order to select the optimum values of system parameter under the given operating conditions.

\section{NOMENCLATURE}

$$
\begin{aligned}
& I=\text { Insolation, } \mathrm{Wm}^{-2} \\
& \Delta T=\text { Temperature rise of air in the collector, }{ }^{\circ} \mathrm{C} \\
& T_{b i}=\text { Initial temperature of bed, }{ }^{\circ} \mathrm{C} \\
& T_{i b}=\text { Inlet temperature to the bed, }{ }^{\circ} \mathrm{C} \\
& T_{a m b}=\text { Ambient temperature, }{ }^{\circ} \mathrm{C} \\
& Q_{a t}=\text { Total available energy stored in the bed at the end } \\
& W_{t}=\text { of charging, } \mathrm{J} \\
& \psi=\text { Total energy consumption by fan at the end of } \\
& \psi_{o}=\text { Sphericity, dimensionless } \\
& \varepsilon_{0}=\text { Optimum value of sphericity, dimensionless } \\
& \varepsilon_{o}=\text { Optimum value of void fraction, dimensionless }
\end{aligned}
$$

\section{REFERENCES}

[1] Schmidt, F.W.; Willmot, A.J. Thermal Energy Storage and Regeneration, McGraw-Hill Book Co., 1981.

[2] Sagara, K.; Nakahara, N. Thermal performance and pressure drop of packed beds with large storage materials. Solar Energy, 1991, 47, 157-163.

[3] Singh, R.; Saini, R.P.; Saini, J.S. Nusselt number and friction factor correlations for packed bed solar energy storage system having large sized elements of different shapes. Solar Energy, 2006, 80, 760-771.

[4] Singh, R.; Saini, R.P.; Saini, J.S. Simulated performance of packed bed solar energy storage system having storage material elements of large size-Part I. Open Fuels Energy Sci. J., 2008, 1, 91-96.

[5] Singh, R.; Saini, R.P.; Saini, J.S. Simulated performance of packed bed solar energy storage system having storage material elements of large size-Part II. Open Fuels Energy Sci. J., 2008, 1, 97-101.

[6] Singh, R.; Saini, R.P.; Saini, J.S. Simulated performance of packed bed solar energy storage system having storage material elements of large size-Part III. Open Fuels Energy Sci. J., 2008, 1, 102-107.

[7] Torab, H.; Beasley, D.E. Optimization of packed bed thermal energy storage unit. J. Solar Energy Eng. (Trans. ASME), 1987, 109, 170-175. 